\title{
Design of 4-stage Marx generator using gas discharge tube
}

\author{
Wijono, Zainul Abidin, Waru Djuriatno, Eka Maulana, Nola Ribath \\ Department of Electrical Engineering, Universitas Brawijaya, Indonesia
}

\section{Article Info \\ Article history: \\ Received Sep 2, 2019 \\ Revised Dec 10, 2019 \\ Accepted Jun 12, 2020 \\ Keywords: \\ Gas discharge tube \\ Impulse voltage \\ Marx generator \\ Storage capacitor \\ Voltage multiplier}

\begin{abstract}
In this paper, a Marx generator voltage multiplier as an impulse generator made of multi-stage resistors and capacitors to generate a high voltage is proposed. In order to generate a high voltage pulse, a number of capacitors are connected in parallel to charge up during on time and then in series to generate higher voltage during off period. In this research, a $6 \mathrm{kV}$ Marx generator voltage multiplier is designed using gas discharge tube (GDT) as an electronic switch to breakdown voltage. The Marx generator circuit is designed to charge the storage capacitor for high impulse voltage and current generator applications. According to IEC 61000-4-5 class 4 standards, the storage capacitor must be charged up to $4 \mathrm{kV}$. The results show that the proposed Marx generator can produce voltages up to $6.8 \mathrm{kV}$. However, the storage capacitor could be charged up to $1 \mathrm{kV}$, instead of $4 \mathrm{kV}$ in the standard. That is because the output impulse voltage has narrow time period.
\end{abstract}

This is an open access article under the CC BY-SA license.

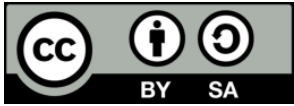

\section{Corresponding Author:}

Wijono,

Department of Electrical Engineering,

Universitas Brawijaya,

Jl. MT Haryono 167 Malang, Indonesia.

Email: wijono@ub.ac.id

\section{INTRODUCTION}

High impulse voltage generation has been developed since 19th century. In order to generate high impulse voltages, voltage multiplier is necessary. Marx generator is a circuit with multi-stage voltage multiplier [1, 2]. Since the Marx generator has many applications in various fields, it has been attracting many researcher's attention, for example development of 6-stage Marx generator with $100 \mathrm{kA}$ output and 12-stage Marx generator with $5 \mathrm{~kJ}$ output [3, 4], switch-capacitor cells used for solid-state Marx generator to produce -4 to $4-\mathrm{kV}$ amplitude is presented in [5], pulse-forming network based Marx generator was reported in [6], and output voltage characteristics based on spark gap breakdown voltage was evaluated in [7]. On the other hand, the Marx generator is also useful for charging storage capacitor (SC) of voltage-current impulse generator. Step-up dc-dc converter or transformer is also available to support the SC charging. Increasing turn ratio of transformer means increasing voltage [8-9]. However, it has disadvantages of big dimension, heaviness, core losses, high cost, and tend to be non-portable [10-12]. Combinational (voltage-current) impulse generator is not easy to achieve commercially. However, requirement of the combinational impulse generator is needed for testing safety equipment against high voltage. The combinational impulse generator must follow the IEC 61000-4-5 standard [13].

In order to generate impulse voltages up to $2 \mathrm{kV}$, usually Marx generator uses air as a medium for isolation of breakdown voltage on the spark gap. Magnitude of breakdown voltage is influenced by air temperature, air pressure, air humidity, distance between electrodes, and kind of electrodes [14]. Gas discharge tube (GDT) is well known as a protective device [15-19]. In this work, design of a 4-stage, compact, inexpensive, and portable Marx generator circuit with GDT as an isolation medium is proposed and evaluated experimentally. 


\section{PROPOSED MARX GENERATOR SPECIFICATION}

This section describes the details of a 4-stage Marx generator designed for charging SC. The Marx generator circuit uses GDT as spark unit. The goal is to achieve charging SC up to $4 \mathrm{kV}$ during maximum 10 seconds. The Marx generator circuit, shown in Figure 1 [20], is made of number of resistors and capacitors arranged in 4 stages to get higher voltages. The arrangement makes the capacitors to be charged in parallel and then discharge in series. Serial discharge makes the output voltage multiplied due to the number of stages. In this research, the output voltage is multiplied 4 times. The serial discharge happens after the GDT breakdown. The output voltage is expressed in (1). When each stage generates a different voltage, the output voltage of n-stage is expressed by (2).

$$
\begin{aligned}
& V_{o}=n \times V_{i n} \\
& V_{n}^{\prime}=V_{n}+V_{n-1}
\end{aligned}
$$

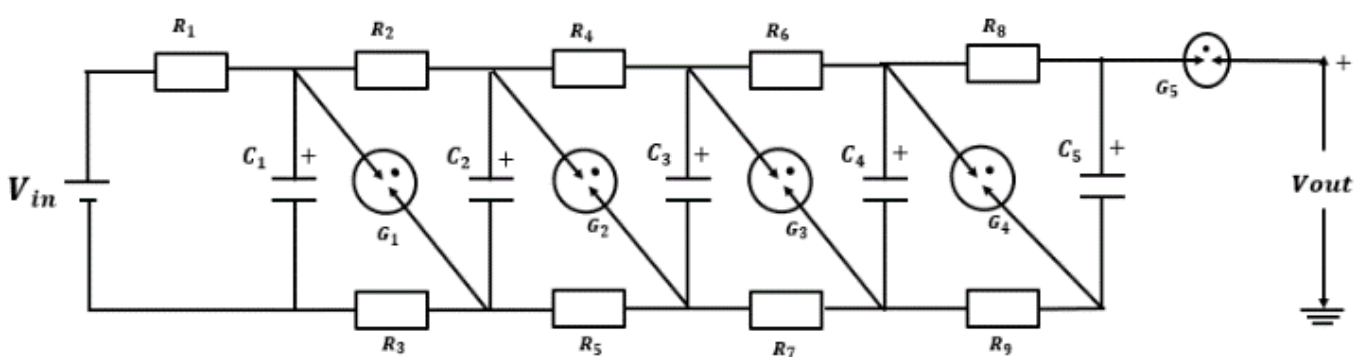

Figure 1. Circuit schematic of a 4-stage Marx generator with GDT

The GDT is an electronic component with gas plasma and used to eliminate transient voltage. As a protective device, the GDT has high insulation resistance, low capacitance and low leakage current to ensure minimal effects on normal equipment operations [21]. In simple terms, the construction of the GDT consists of two or more electrodes. Inside the GDT, there is a gas-filled gap as an insulator. When spark over value of the GDT is reached by voltage disturbance, virtual short will happen. Two-electrodes GDT is symbolized in Figure 1 with names of G1-4 and physically shown in Figure 2 [22]. When DC voltage source (Vin) is given to the circuit as shown in Figure 1 capacitors will be filled in parallel. This is called as charge mode. Then, at a certain voltage level or when the voltage reaches the breakdown voltage value, the spark gap will work and break through. It causes the first stage capacitor will be connected in series with the second stage capacitor. It happens similarly for the next stage. In this condition the spark gap has function as a closed switch. After the spark occurs, the voltage of each stage will be added to the next stage because of the series. After that, the capacitor works as a voltage source, so that the output voltage (Vout) is equal to $n x V c$. This is called as release mode. Finally, the input voltage is multiplied.

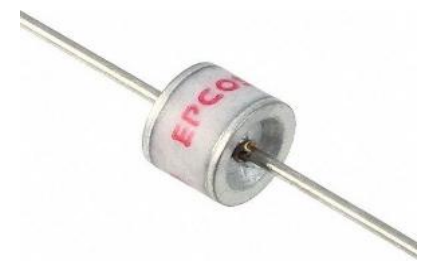

Figure 2. Physical display of GDT

There are two methods for charging a SC, namely charging by rectifying high AC voltage and charging with another capacitor (flash charging). In order to charge the SC, both methods must have higher voltages than the SC voltage. It is intended that the current can flow from higher voltage to lower voltage. The first method rectifies the high AC voltage from a step-up transformer to DC voltage. However, this method has various disadvantages, especially in the transformer. Step-up transformer is heavy and has an expensive price, wide dimensions, and various electrical losses. The second method has advantages in charging time. For the same voltage charging, the capacitor method is faster than the transformer one. 
The output voltage produced by the Marx generator circuit takes the form of a very short impulse. The output voltage of the Marx generator circuit is expected to produce a voltage of $6 \mathrm{kV}$. Determination of the number of stages ( $n$ ) is based on the source of the Marx generator circuit voltage supply. The voltage source available in the laboratory has maximum output of $2 \mathrm{kV}$, in order to reach $6 \mathrm{kV}, 4$ levels are needed according to (1).

The Marx generator circuit realization is shown in Figure 3 and charged by input voltage of $1.5 \mathrm{kV}$. Resistor value is generally in the range of $10 \Omega$ to $100 \mathrm{k} \Omega$. Firstly, $10 \mathrm{k} \Omega 5 \mathrm{~W}$ was chosen since it is easy to get in the market [23]. In order to avoid voltage stagnation, minimum value of the capacitor in the Marx generator circuit is $0.1 \mathrm{nF}$. Since it is easy to get in the market, capacitor with $10 \mathrm{nF} 3 \mathrm{kV}$ was chosen. Ten capacitors are parallelized in each stage to get a value of $100 \mathrm{nF}$ [24]. Based on (1) and $V_{\text {in }}=1.5 \mathrm{kV}$, each stage will have $1500 \mathrm{~V}$ voltage. Determination of the GDT value is based on the voltage at each level of the capacitor. Therefore, the suitable GDT is the one with DC spark-over voltage of $1500 \mathrm{~V}$. It is intended to generate $6 \mathrm{kV}$ output voltage for open circuit and $4 \mathrm{kV}$ output voltage for storage capacitor (based on IEC 61000-4-5).

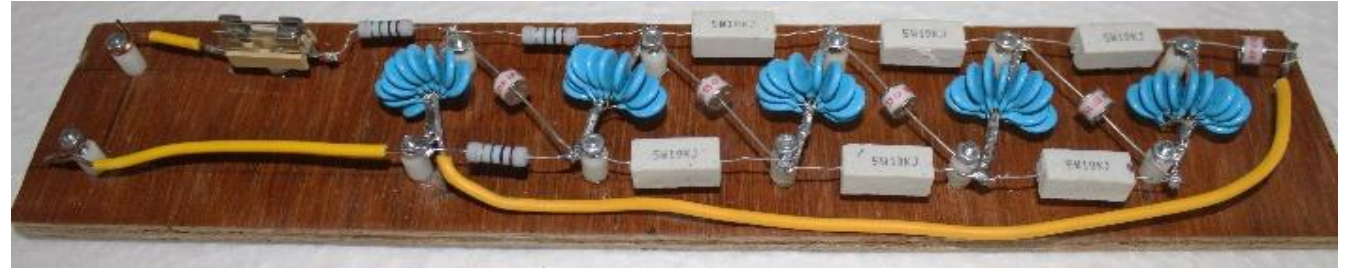

Figure 3. Realization of a 4-stage Marx generator with GDT

\section{RESULTS AND DISCUSSION}

The 4-stage Marx generator was realized for voltage multiplier applications. Some experiments were done to evaluate the performance of the Marx generator. The experimental results are presented based on open circuit (no load) output voltage and SC loaded output voltage (also confirm charging time). The performance data are presented using Hantex MSO5074FG oscilloscope and high voltage probes that have $1000 \mathrm{x}$ attenuation with volts $/ \mathrm{div}=2 \mathrm{kV} / \mathrm{div}$ and time/div of $20 \mu \mathrm{s} / \mathrm{div}$, so that the output waves can be clearly visible. Experimental setup is presented in Figure 4. The distance of each component, cable and electric potential is designed far apart to avoid breakdown voltage. Referring [25], in case of potential $6 \mathrm{kV}$ and 0 volt, it must be separated by minimum distance of $2 \mathrm{~cm}$. Release of capacitor charge can use a circuit consisting of inductor and resistor connected in series to meet the over damped technique. The release of the SC charge uses an inductor that has an insulator. The insulator must be capable of holding the maximum voltage of the $\mathrm{SC}$, which is $4 \mathrm{kV}$.

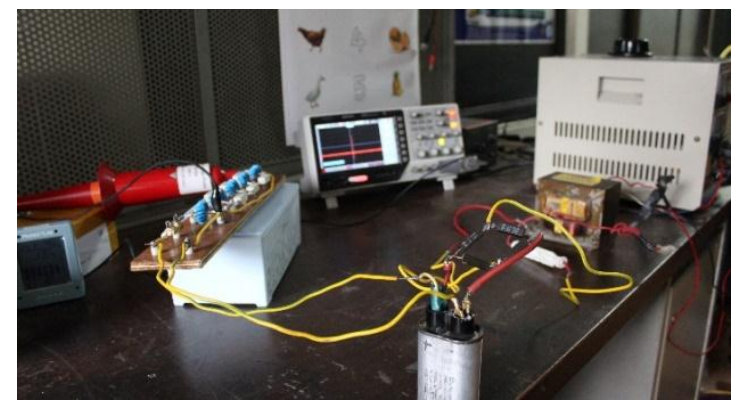

Figure 4. Experimental setup

\subsection{Output voltage with no load}

In this sub section, experiment based on output power is discussed in detail. Marx generator circuit used in this experiment is the same as Figure 1. Each stage of the Marx generator uses $10 \mathrm{k} \Omega 5$ watt resistor as shown in Figure 3. The resistor $R_{1}$ is broken after being charged by input voltage of $1500 \mathrm{~V}$. When $\mathrm{G}_{1}$ is connected as short circuit, condition of stage 1 is illustrated in Figure 5. Then, current flows through $R_{1}$ $\left(I_{\text {in }}\right)$ and is calculated as follows. 


$$
\begin{aligned}
V_{\text {in }} & =I_{\text {in }} \times\left(R_{1}+R_{2}\right) \\
1500 & =I_{\text {in }} \times(10000+10000) \\
I_{\text {in }} & =\frac{1500}{20000} \\
& =0.075 \mathrm{~A}
\end{aligned}
$$

In this case, the resistor cannot handle the current of $0.075 \mathrm{~A}$. Then, the power absorbed by the $\mathrm{R}_{1}$ is derived as follows.

$$
\begin{aligned}
P & =I_{\text {in }}^{2} \times R_{1} \\
& =0.075^{2} \times 10000 \\
& =56.25 \mathrm{~W}
\end{aligned}
$$

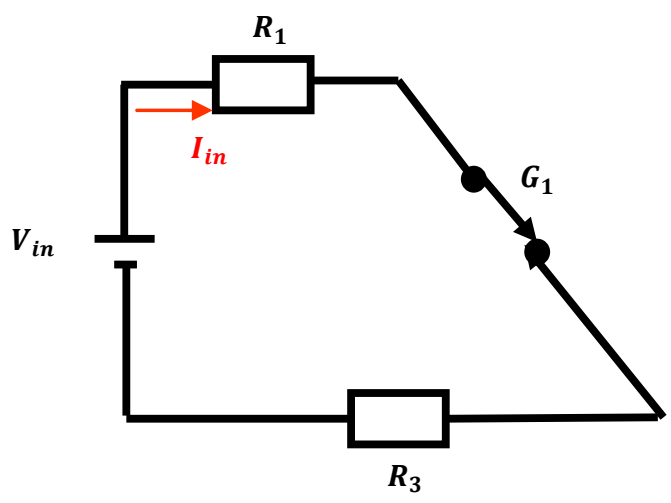

Figure 5. Illustration when G1 is short circuit

As mentioned before, the $\mathrm{R}_{1}$ breaks, the output voltage of the Marx generator is $2.8 \mathrm{kV}$, as shown in Figure 6. Then, the $\mathrm{R}_{1}, \mathrm{R}_{2}$, and $\mathrm{R}_{3}$ are changed by resistor of $1 \mathrm{M} \Omega 1 \mathrm{~W}$. By using $(3,4)$, the current flows through $\mathrm{R}_{1}$ can be limited until $0.75 \mathrm{~mA}$ with power loss of $0.5625 \mathrm{~W}$. Finally, with no load condition, the marx generator can produce impulse output voltage of $6.8 \mathrm{kV}$ as shown in Figure 7.

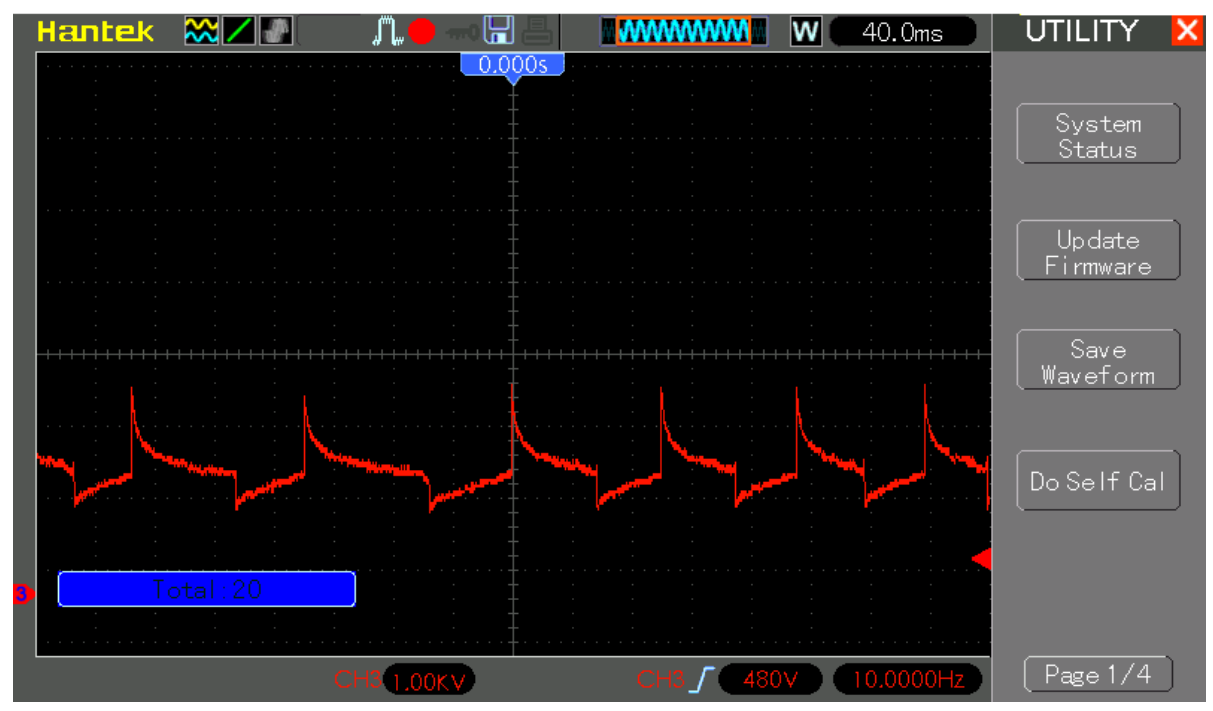

Figure 6. Output voltage with no load $(\mathrm{R}=10 \mathrm{k} \Omega 5 \mathrm{~W})$ 


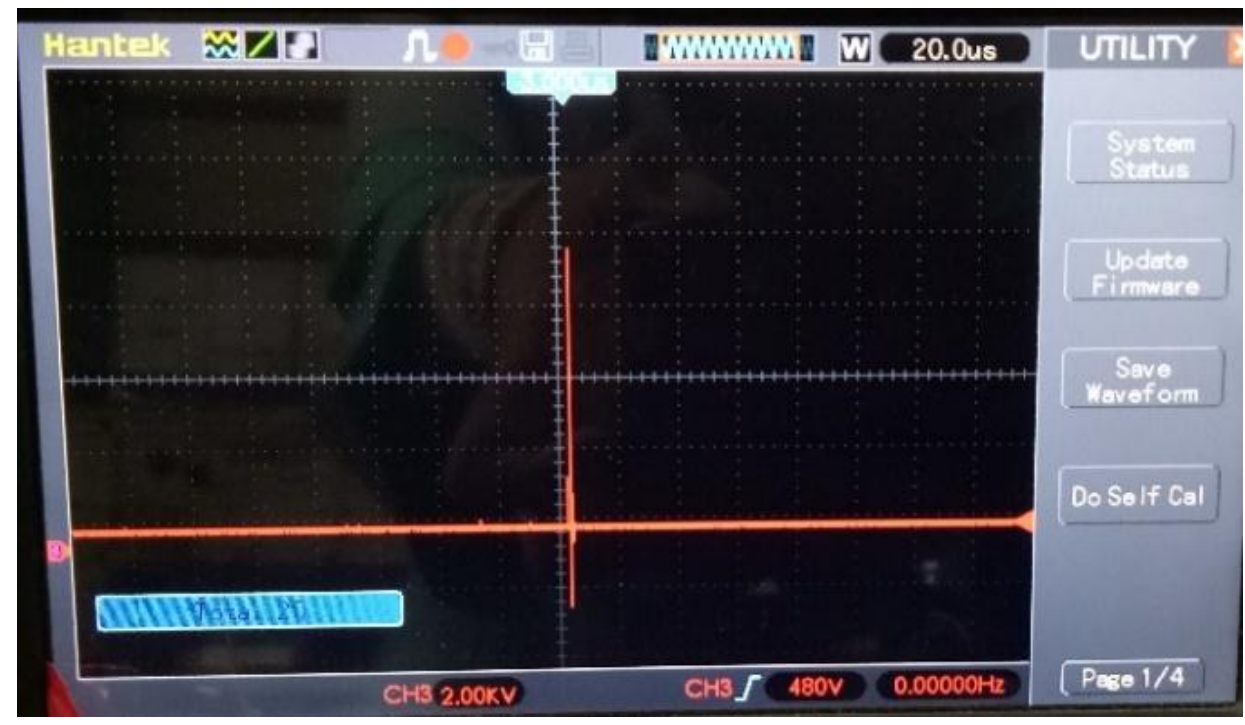

Figure 7. Output voltage with no load $(\mathrm{R}=1 \mathrm{M} \Omega 1 \mathrm{~W})$

\subsection{Output voltage with SC loaded}

Experiment with SC loaded follows the circuit in Figure 1, but the SC of $25 \mu \mathrm{F} 12 \mathrm{kV}$ is connected to the $V_{\text {out }}$. The purpose of this experiment is to find the maximum voltage when charging the SC and prove that the impulse voltage can fill the capacitor. Charging is stopped when each GDT is short-circuit which is indicated by no increase in voltage of the SC and no breakdown of the GDT. For safety, a $20 \mathrm{kV}$ diode is connected in series between the Marx generator circuit and the SC to prevent inverse voltage. Figure 8 shows that the SC is charged until the voltage reaches a maximum of $1 \mathrm{kV}$. After the SC has been charged $1 \mathrm{kV}$ and there is no additional charge at the SC, input is turned off so that the charge on the SC can be discharged. Figure 9 shows the voltage drop is very slow when the input is turned off. This is because of the small intrinsic resistance of the SC. In this case, the Marx generator circuit could not charge the SC according to target, i.e. IEC standard of $4 \mathrm{kV}$, because the SC capacitance is larger than the capacitor in the Marx generator circuit. These experimental results are summarized in Table 1.

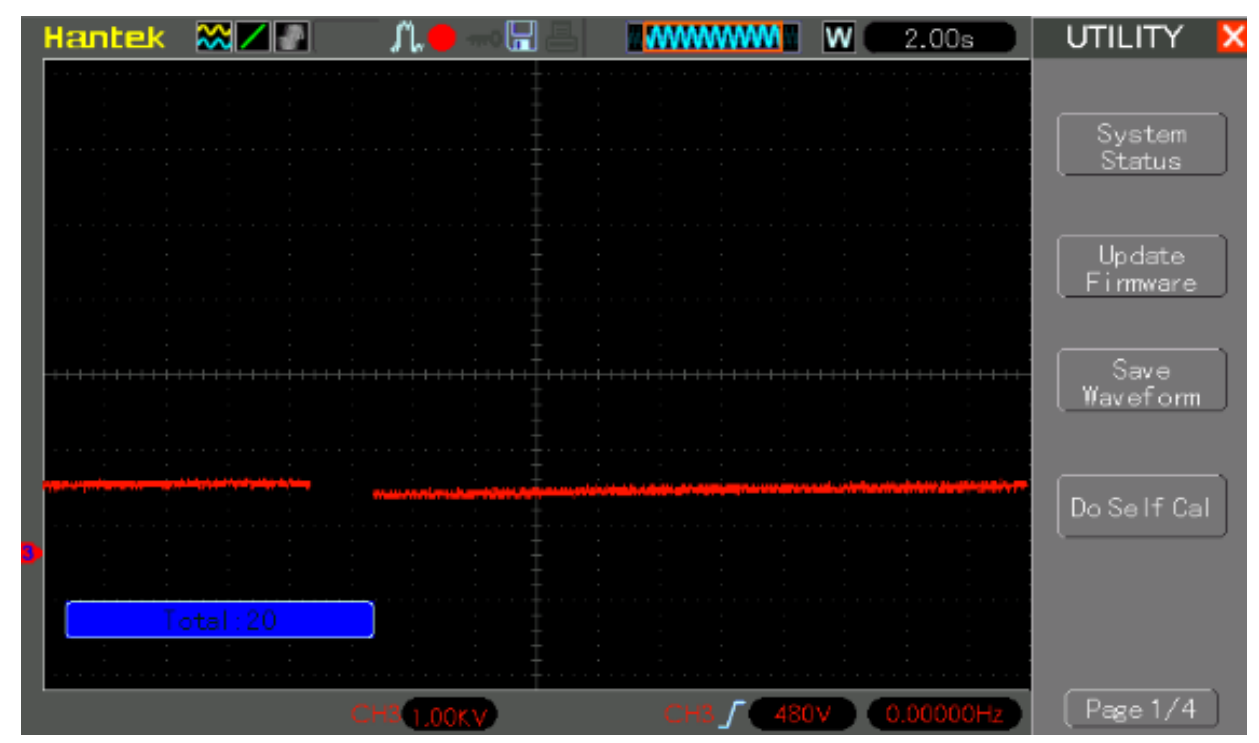

Figure 8. Experimental result of charging SC 


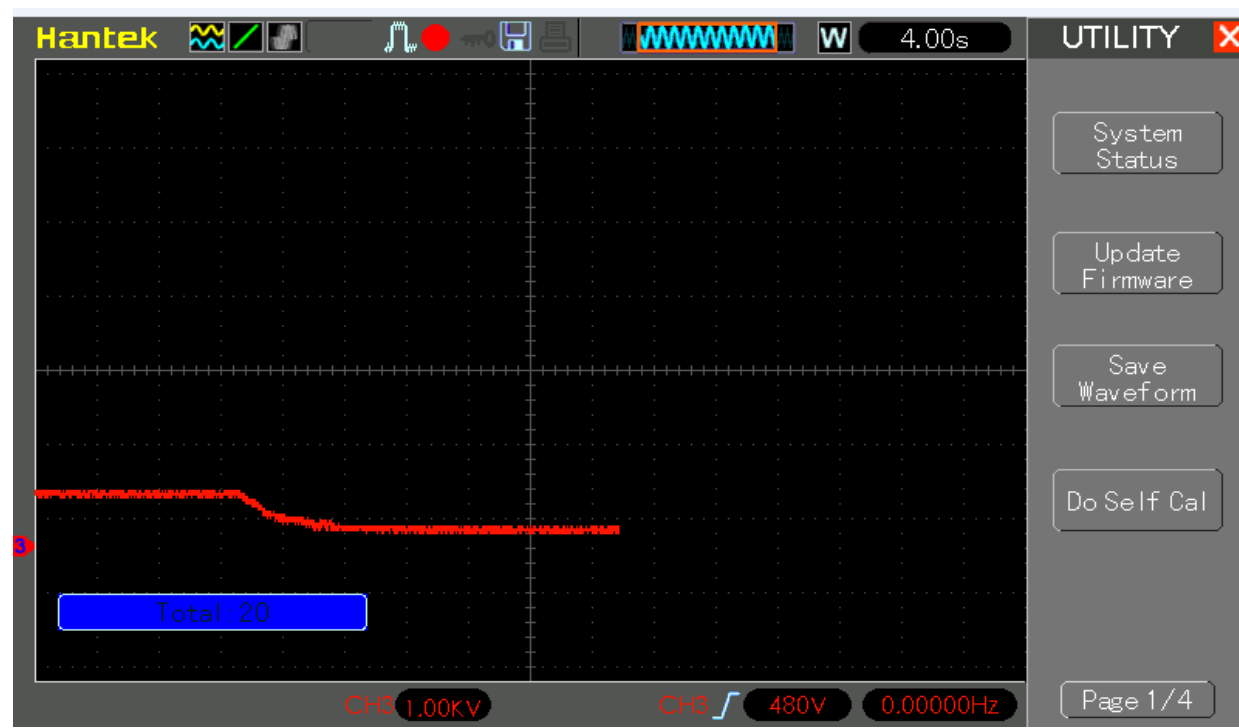

Figure 9. Experimental result of release SC

Table 1. Experimental results compared with target

\begin{tabular}{lll}
\hline & Target & Experiment \\
\hline Voltage charged to SC & $4 \mathrm{kV}$ & $1 \mathrm{kV}$ \\
SC charging time & $10 \mathrm{~s}$ & $20 \mathrm{~s}$ \\
\hline
\end{tabular}

\section{CONCLUSION}

In this paper, Marx generator voltage multiplier has been designed and evaluated experimentally. Based on the open circuit (no load) experimental results, the designed $6 \mathrm{kV}$ Marx generator can multiply voltage and generate impulse voltage until $6.8 \mathrm{kV}$ (peak). However, it just can charge storage capacitor with maximum voltage of $1 \mathrm{kV}$. The designed Marx generator cannot achieve the target when it was loaded with storage capacitor. In the future, further research on analysis of breakdown voltage of GDT is required. Furthermore, bigger resistance value is necessary for the resistor connected series with voltage source and first stage of the Marx generator. It will be current limiter. Development of advanced Marx generator circuit for wider time period output voltage is needed to charge storage capacitor.

\section{REFERENCES}

[1] R. Li and R. Qi, "The design of new compact Marx generator," in Chinese Journal of Electronics, vol. 27, no. 6, pp. 1305-1308, November 2018.

[2] Wijono, E. Maulana, D. D. Putra, and W. Djuriatno, "Plasma generator: Design of six stage Cockcroft-Walton voltage multiplier $12 \mathrm{kV}$ for impulse voltage generation," TELKOMNIKA Telecommunication, Computing, Electronics and Control, vol. 17, no. 4, pp. 1890-1897, August 2019.

[3] M. Lehmann, "High energy output marx generator design," 2010 IEEE International Power Modulator and High Voltage Conference, Atlanta, GA, pp. 576-578, 2010.

[4] A. S. Yudin, S. S. Martemyanov, A. A. Bukharkin, I. V. Bugaev, and E. G. Krastelev, "Triggered spark gap switch with gas circulation for repetitively operated multistage marx generator," 2018 20th International Symposium on High-Current Electronics (ISHCE), Tomsk, pp. 166-169, 2018.

[5] T. Sakamoto and H. Akiyama, "Solid-state dual Marx generator with a short pulsewidth," in IEEE Transactions on Plasma Science, vol. 41, no. 10, pp. 2649-2653, Oct. 2013.

[6] H. Li, H. Ryoo, J. Kim, G. Rim, Y. Kim, and J. Deng, "Development of rectangle-pulse Marx generator based on PFN," in IEEE Transactions on Plasma Science, vol. 37, no. 1, pp. 190-194, Jan. 2009.

[7] A. Razi Kazemi, K. Niayesh, and A. A. Shayegani, "Effects of statistical characteristics of the output voltage in compact Marx generator on insulation test results," 2010 10th IEEE International Conference on Solid Dielectrics, Potsdam, pp. 1-4, 2010.

[8] M. J. Ebrahimi and A. H. Viki, "Interleaved high Step-up DC-DC converter with diode capacitor multiplier cell and ripple-free input current," Bulletin of Electrical Engineering and Informatics, vol. 4, no. 4, pp. 289-297, 2015.

[9] L. Yang, T. Liang, H. Lee, and J. Chen, "Novel high step-up DC-DC converter with coupled-inductor and voltagedoubler circuits," in IEEE Transactions on Industrial Electronics, vol. 58, no. 9, pp. 4196-4206, Sept. 2011. 
[10] E. Babaei, A. Mofidi, and S. Laali, "Analysis of the transformerless boost DC-DC converter with high voltage gain in different operating modes and critical inductance calculations," Bulletin of Electrical Engineering and Informatics, vol. 4, no. 2, pp. 136-146, June 2015.

[11] M. R. Islam, Y. Guo, and J. Zhu, "A multilevel medium-voltage inverter for step-up-transformer-less grid connection of photovoltaic power plants," in IEEE Journal of Photovoltaics, vol. 4, no. 3, pp. 881-889, May 2014.

[12] B. Axelrod, Y. Berkovich, and A. Ioinovici, "Switched-capacitor/switched-inductor structures for getting transformerless hybrid DC-DC PWM converters," in IEEE Transactions on Circuits and Systems I: Regular Papers, vol. 55, no. 2, pp. 687-696, March 2008.

[13] International Electrotechnical Commission, "IEC 61000-4-5 Standard Overview: Lightning and Industrial Surges Model," 2013.

[14] L. Ming, F. Sahlen, G. Wu, G. Asplund, and B. Jacobson, "Humidity effects on dielectric strength of air-gaps for indoor HV installations," CEIDP '05. 2005 Annual Report Conference on Electrical Insulation and Dielectric Phenomena, Nashville, TN, USA, pp. 43-46, 2005.

[15] Q. Zhou, Y. Zhao, F. Liu, and J. Zhang, "Comparative study of the newly-published IEC 61643-311 and -312 for lightning protective component GDT," 2014 International Conference on Lightning Protection (ICLP), Shanghai, pp. 854-856, 2014.

[16] C. A. McCreary and B. A. Lail, "Choosing the appropriate gas discharge tubes (GDT) for avionics lightning protection," in IEEE Electromagnetic Compatibility Magazine, vol. 2, no. 3, pp. 57-59, 3rd Quarter 2013.

[17] M. Pejovic, M. Pejovic, R. Maric, L. Timotijevic, and K. Stankovic, "Delay response of gas discharge tubes," in Photonics and Electromagnetics Research Symposium (PIERS), pp. 1156-1159, 2012.

[18] M. Bizjak, M. Bekovic, and A. Hamler, "Spark breakdown in gas-discharge-tube surge arrester at voltage pulse," in IEEE Transactions on Power Delivery, vol. 30, no. 3, pp. 1552-1560, June 2015.

[19] M. Žumer, B. Zajec, R. Rozman, and V. Nemanič, "Breakdown voltage reliability improvement in gas-discharge tube surge protectors employing graphite field emitters," Journal of Applied Physics, vol. 111, no. 8, p 083301, 2012.

[20] J. N. Nasab, A. Hadizade, S. Mohsenzade, M. Zarghany, and S. Kaboli, "A Marx-based generator with adjustable FWHM using a controllable magnetic switch," in IEEE Transactions on Dielectrics and Electrical Insulation, vol. 26, no. 2, pp. 324-331, April 2019.

[21] Y. Naito, S. Yanagawa, T. Kawabata, and K. Yamamoto, "Response characteristics of diode gas discharge tubes," 2012 International Conference on Lightning Protection (ICLP), Vienna, pp. 1-4, 2012.

[22] IEEE "Guide for the application of surge-protective components in surge protective devices and equipment ports-part 1: Gas discharge tubes (GDTs)," in IEEE Std C62.42.1-2016, pp.1-45, Dec. 2016.

[23] M. S. Naidu and V. Kamaraju, "High voltage engineering, 2nd edition," New Delhi: Tata McGraw Hill Education Private Limited, 1996.

[24] G. Babaji, "Design and construction of a $12 \mathrm{kV}$ D.C. power supply," Bayero Journal of Pure and Applied Sciences, vol. 2, no. 2, pp. 175-184, 2009.

[25] K. N. Kiousis, A. X. Moronis, and W. G. Früh, "Analysis of the electric field distribution in a wire-cylinder electrode configuration," in 2013 International Conference on Applied Mathematics and Computational Methods in Engineering, pp. 164-170, 2013. 